\title{
Todos Somos Juárez. Competition in state-making y la guerra contra el narcotráfico (2006-2012)
}

\author{
Todos Somos Juárez. Competition in state-making \\ and the war on drugs (2006-12)
}

\author{
ESTEBAN ARRATIA \\ Academia Nacional de Estudios Políticos y Estratégicos (ANEPE)

\section{Cómo citar/Citation} \\ Arratia, E. (2017). Todos Somos Juárez. Competititon in state-making y la guerra contra el narcotráfico (2006-2012). \\ Revista Española de Ciencia Política, 43, 83-1 11. Doi: https://doi.org/10.21308/recp.43.04
}

\section{Resumen}

En el Foro Económico Mundial de 2016, Ciudad Juárez destacó como una de las ciudades latinoamericanas que lograron una notable reducción del crimen y la violencia asociada al narcotráfico, dejando atrás el estigma de ser la ciudad más peligrosa del mundo. Ante lo anterior cabe preguntarse: ¿cómo se generó tal cambio? Durante la guerra contra el narcotráfico (2006-2012), el expresidente Felipe Calderón desplegó al ejército en zonas críticas asediadas por los cárteles de la droga. No obstante, tras una masacre ocurrida en Juárez -urbe fronteriza sacudida por la violencia asociada al narcotráfico-, el Gobierno federal dio un giro en su enfoque militarizado. Como resultado, las operaciones fueron acompañadas por un inédito programa de ayuda socioeconómica: Todos Somos Juárez, cuyo objetivo era construir comunidades resistentes a la penetración del crimen organizado. A partir del concepto de "construcción competitiva de Estado" (competition in state-making), el presente trabajo analiza en primer lugar el diseño e implementación de la mencionada iniciativa, luego realiza un balance de los resultados obtenidos tras su ejecución y, por último, identifica las principales lecciones que se pueden extraer del caso mexicano. La principal conclusión del artículo es que la instrumentación de Todos somos Juárez se fundamentó en tres pilares estratégicos: enfoque holístico, activa participación ciudadana y coordinación entre los tres niveles de gobierno (federal, estatal y municipal).

Palabras clave: construcción competitiva de Estado, guerra contra el narcotráfico, crimen organizado, comunidades resistentes, México. 


\begin{abstract}
In the 2016 World Economic Forum, Ciudad Juarez stood out as one of the Latin American cities that achieved a remarkable reduction of drug trafficking-related crimes and violence, leaving thus behind the stigma of being the most dangerous city in the world. Taking this into consideration, the question could be raised: how did such change emerge? During the war on drugs (2006-2012), former President Felipe Calderon deployed the army in critical areas besieged by drug cartels. However, and following a massacre in Juarez -a border city shaken by drug trafficking-violence-, the Federal Government took a new turn in its militarized approach. As a result, the military operations were accompanied by an unprecedented socio-economic aid program: Todos Somos Juarez aimed at building resilient communities to the penetration of organized crime. Based on the concept of "competition in state-making", this paper first analyzes the design and implementation of the above-mentioned initiative; then, it performs an assessment of the results obtained after his execution; and finally, it identifies some key lessons that can be drawn from the Mexican experience. The amin conclusion of the article is that Todos Somos Juarez was based on three strategic pillars: holistic approach, active citizen participation and coordination between the three levels of Government (federal, state and municipal).
\end{abstract}

Keywords: competition in state-making, war on drugs, organized crime, resilient communities, Mexico.

\title{
INTRODUCCIÓN
}

Según un informe elaborado por el Centre for the Democratic Control of Armed Forces titulado Armed Non-State Actors: Current Trends \& Future Challenges, el crimen organizado es un fenómeno económico que puede asumir roles institucionales y transformarse en poder paralelo capaz de proveer no solo oportunidades económicas, sino también regular la estructura social de comunidades enteras, ofreciendo múltiples bienes y servicios públicos a la población en aquellas áreas donde su presencia es más significativa. El resultado de este proceso es la construcción de legitimidad, particularmente en Estados que atraviesan por situaciones de conflicto o propensos a devenir Estados fallidos (DCAF, 2012).

En el caso de México, el principal vacío radica en la incapacidad del Estado para restablecer su presencia en los territorios, no solo desde la perspectiva de la seguridad, sino también con una oferta integral de bienes y servicios, o sea, "la presencia integral del Estado tiene dos niveles: el primero son las acciones sociales que servirán para restablecer la confianza entre el poder coercitivo del Estado y los ciudadanos, y en un segundo nivel están las acciones que tienen que ver con las responsabilidades específicas del Estado en dichos lugares. Las primeras tienen un valor operacional inmediato para ocupar el terreno, motivar a las fuerzas sobre su rol pacificador y modificar la actitud de los habitantes hacia los policías. Las segundas se proponen transformar los factores que reproducen la violencia y los delitos» (Villalobos, 2015). 
Así, «mientras más ausente se encuentre el Estado o mientras más deficientes sean los servicios públicos que proporciona más susceptibles serán las comunidades de depender de las organizaciones delictivas que promueven el tráfico de drogas y otras economías ilegales y de convertirse en sus partidarios" (Felbab-Brown, 2013: 153). En contraste, si el Estado provee estos servicios a la población y se mejora su bienestar, esto desalentará a los ciudadanos a desarrollar actividades ilícitas como fuente de ingresos y como resultado se reducirá su apoyo al crimen organizado, dificultando aún más su penetración. No debe perderse de vista que el desarrollo de economías criminales se encuentra directamente vinculado a la carencia de medios de subsistencia alternativos en segmentos poblacionales postergados. Por tal razón, las intervenciones gubernamentales deberían focalizarse particularmente en los denominados Ninis (jóvenes que ni trabajan, ni estudian): el estrato demográfico más proclive a ser reclutado por los cárteles.

Desde esa perspectiva, Felbab-Brown (2010) sostiene que los gobiernos deben conceptualizar su respuesta institucional contra la violencia como una "construcción competitiva de Estado" (competition in state-making) entre organismos públicos y actores armados no estatales cuyo objetivo final es ganarse la lealtad de la población. En ese sentido, cabe señalar que "[c]ualquier estructura, lícita o ilícita, presente en estas zonas, ofrece incentivos financieros y cierto nivel de estabilidad para las familias. Las [comunidades] tienen la opción de apoyar o rechazar ya sea a los grupos criminales o a las fuerzas de seguridad, con base en su percepción de cuál puede generarles un mayor beneficio» (Patterson y Blain, 2014: 61). Por consiguiente, una respuesta política adecuada a este fenómeno debe proporcionar vías de acceso a bienes y servicios públicos con el propósito de que las personas transfieran su lealtad al Estado, fortaleciendo los lazos entre éste último y los ciudadanos, de manera tal que los vínculos existentes entre la población y los actores armados no estatales como los carteles se debiliten.

En otras palabras, la participación estratégica de estos actores no estatales afecta el propósito fundamental del Estado y tiene implicaciones políticas pues actúan como constructores competitivos de Estado, mermando su funcionalidad y legitimidad. De ese modo, mientras más orden, seguridad y bienes económicos brinden para ganarse los corazones y mentes de la población local, mayor es la posibilidad de convertirse en gobernantes protoestatales de facto con un alto grado de capital político gracias a «la aceptación y legitimidad suficiente de la población para asegurar su tolerancia, si no directamente, su preferencia por encima del Estado, e incluso su negativa a cooperar con él en el combate contra los criminales, reduciendo la capacidad de respuesta institucional» (Felbab-Brown, 2011a: 6). Por lo tanto, la promoción de apoyo masivo se asocia al concepto de construcción competitiva de Estado, que se traduce en una entidad gubernamental con un grado de legitimidad y capital político.

No obstante, los programas socioeconómicos para disminuir la violencia no son un sustituto de la seguridad. Por tal motivo es que previo a la reconstrucción de Estado debiera aplicarse un enfoque militarizado de la seguridad para recuperar ese 
territorio ${ }^{1}$, romper el poder intimidatorio de las organizaciones criminales, restablecer la autoridad del Estado y disponerlo a la correcta implementación de programas gubernamentales. O sea, las intervenciones sociales preventivas en lugares dominados por delincuentes fracasan si no se recupera antes la autoridad del Estado. Recuperar el terreno implica que los criminales deben perder estabilidad, confort, movilidad, poder de intimidación y capacidad de concentrarse para actuar impunemente. Como asegura Villalobos (2010): «No se puede entrar a una zona dominada por [cárteles] con planes de asistencia tipo Madre Teresa y tampoco es previsible incentivar la participación ciudadana en sitios donde el narcotráfico tiene atemorizada a la sociedad». En resumidas cuentas, el éxito de la construcción competitiva de Estado radica en su potencial disuasivo frente a las organizaciones criminales y la demostración a la sociedad de que el Estado es más fuerte que los delincuentes.

Un ensayo de este modelo durante el periodo examinado fue el proyecto Todos Somos Juárez (en adelante, TSJ) desarrollado en la ciudad homónima. De esa manera, a partir del concepto de "construcción competitiva de Estado" (competition in state-making), el presente trabajo analiza en primer lugar el origen del programa; luego analiza el diseño e implementación de la mencionada iniciativa; a continuación se realiza un balance de los resultados obtenidos tras su ejecución y, con posterioridad, evalúa su posible emulación en otras zonas afectadas por la violencia asociada al narcotráfico. Finalmente, identifica las principales lecciones que pueden extraerse del caso mexicano.

\section{¿CÓMO NACIÓ TSJ?}

Ciudad Juárez, situada en el estado de Chihuahua, es una ciudad con mucho patrimonio histórico, donde habitan aproximadamente 1,3 millones de personas. Apodada como Paso del Norte, fue escenario de la ofensiva triunfal del presidente Benito Juárez ante el Imperio de Maximiliano y del triunfo de Francisco Madero que puso fin al Porfiriato (1830-1915). Pero en las últimas décadas, el libre comercio creó una fuerte expansión del sector manufacturero de exportación en México. En ese sentido, Juárez se convirtió en una meca para las maquiladoras, cuya producción se centra en el mercado estadounidense.

Desde los años ochenta del pasado siglo, gente de todo el país emigró a urbes fronterizas industriales como Ciudad Juárez, en busca de mejores oportunidades laborales. En efecto, su población aumentó el doble entre 1985 y 2010 (Calderón, 2013).

1. Recuperación del control territorial es el despliegue, en un espacio determinado, de fuerzas militares y/o policiales que, combinando posiciones fijas, patrullas móviles, fuerzas de reacción, redes de inteligencia ciudadana y, en algunos casos, vigilancia aérea, se propone disuadir delincuentes, detectar delitos en fase temprana, frustrarlos en flagrancia o lograr capturas por persecución inmediata a quienes los hayan cometido (Villalobos, 2015). 
Sin embargo, ese crecimiento demográfico no se vio acompañado de la necesaria inversión en infraestructura y servicios básicos, sino solamente en los aspectos necesarios para que se instalaran fábricas, sin considerar las necesidades de cientos de miles de personas que se trasladaron a Juárez para trabajar en ellas. Tanto el Gobierno federal como el estatal y local permitieron que la ciudad absorbiera este enorme aumento de población sin garantizar el acceso a servicios básicos como infraestructura, educación, vivienda o salud para los hijos de obreros de las maquiladoras. En este contexto de vulnerabilidad socioeconómica crecieron miles de niños y jóvenes, donde comenzaron a abundar las adicciones, la violencia y el delito. Así, una de las características de esta nueva Ciudad Juárez era la inseguridad, la falta de oportunidades económicas para sus habitantes y un tejido social resquebrajado.

FIgURA 1.

Ciudad Juárez

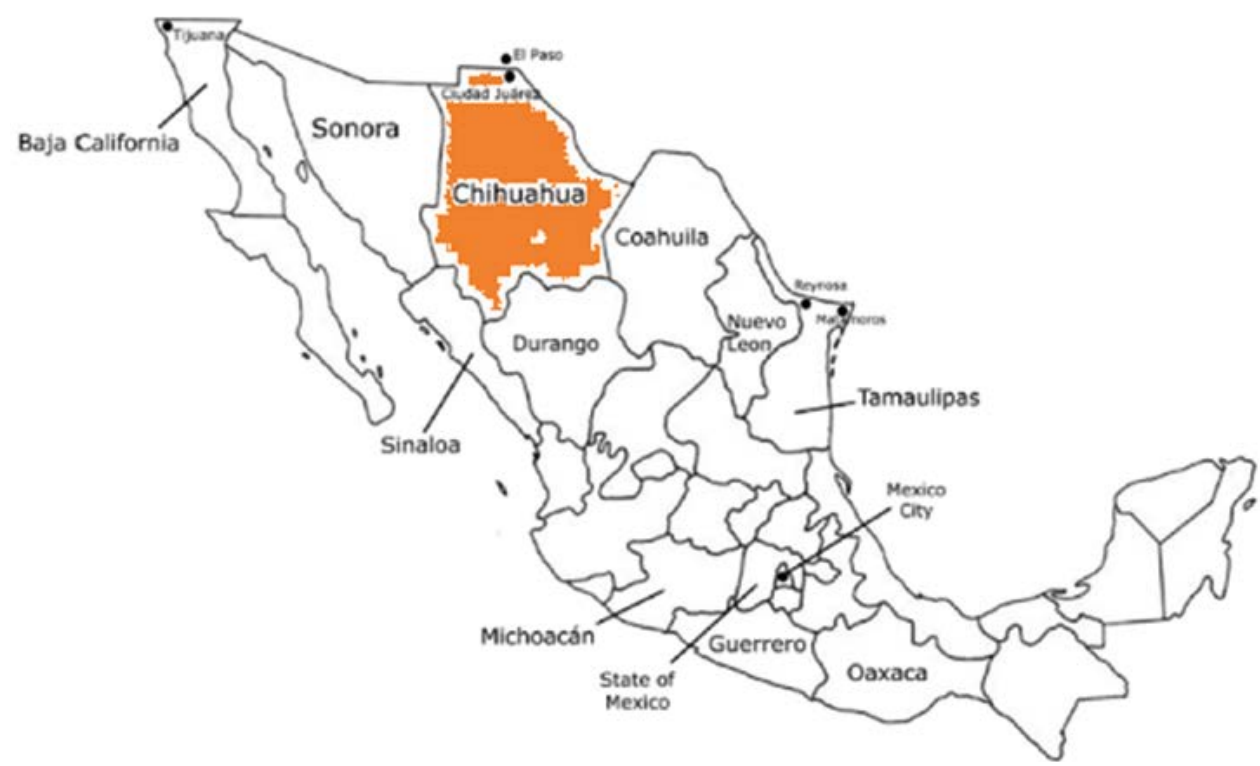

Fuente: Meyer (2010: 3).

A inicios del sexenio calderonista, México atravesaba una crisis de seguridad. Tras décadas de pasividad estatal, los grupos criminales ganaron fuerza, afectando gravemente la vida de ciudadanos en diversas zonas del país. Sin embargo, la situación de Juárez fue particularmente crítica durante gran parte del mandato del expresidente panista, superando más de 3000 homicidios en 2010, es decir, una tasa de más de 200 por cada 100000 habitantes, peor que la registrada en ciudades como Kandahar, Caracas o Bagdad; cifra más de diez veces superior a la tasa nacional de México y treinta veces el promedio global, situación que llevó a la ciudad a ganarse el honroso título de «la ciudad más violenta del mundo» entre 2008 y 2010 (Redacción, 2011). 
Siguiendo el análisis de Gutiérrez (2010), es posible distinguir cuatro secuencias que han actuado como detonantes de la violencia en aquel sitio:

a) en primer lugar, el arresto de Alfredo Beltrán Leyva, alias el Mochomo: la división entre dos viejos aliados que habían cooperado en el control de lucrativas rutas de narcotráfico tras el desprendimiento de la organización Beltrán Leyva del Cártel de Sinaloa, sumado a una coalición de organizaciones (Beltrán Leyva-Zetas-Juárez) para desplazar al Cártel de Sinaloa del paso transfronterizo Ciudad Juárez-El Paso. Esta secuencia de hechos actuó como combustible que encendió el conflicto en Juárez.

b) En segundo término, los cárteles contrataron sicarios para sostener la guerra, lo que causó un enrolamiento masivo de pandilleros. Las pandillas de Ciudad Juárez se alinean con los bandos en conflicto y los cárteles proveen de armas a las pandillas. Esta secuencia de hechos tiene el efecto de amplificar el conflicto, al engrosar los recursos humanos y el armamento con que cuentan los bandos en disputa.

c) En tercer lugar, ningún bando tiene capacidad suficiente para derrotar al otro y las autoridades locales no intervienen en la confrontación directa de los bandos: las instituciones de seguridad y procuración de justicia no tienen capacidad para prevenir, detectar e investigar la gran mayoría de hechos violentos, ni para sancionar a culpables. Se registran pocas aprehensiones y estas son de carácter aleatorio, lo cual permite que prevalezca un clima de impunidad. Estos hechos contribuyen a acelerar la intensidad del conflicto intercartel a gran escala, generando un efecto de escalamiento y multiplicador.

d) Por último, al acentuarse, la violencia incorpora más organizaciones criminales y más pandillas en las filas de cada bando. El descabezamiento de tales organizaciones y pandillas propicia su fragmentación, lo que da paso al desplazamiento territorial de algunas organizaciones y pandillas por la dinámica de las disputas. Estos hechos tienen el efecto de derramar o contagiar la violencia a espacios donde no existía previamente, con lo que aumenta el número de localidades o municipios con violencia, por lo que se ensancha el área en que se registran ejecuciones.

Las cuatro secuencias descritas con anterioridad ayudan a entender la dinámica de la violencia en Juárez. Empero, conviene no subestimar los siguientes factores explicativos en relación con su crecimiento sistemático:

a) Ubicación geoestratégica. Ciudad Juárez es un municipio muy codiciado por las organizaciones narcotraficantes, pues es el punto de cruce fronterizo mejor ubicado para mover droga desde El Paso (Texas), tanto a ciudades del este como del oeste de Estados Unidos.

b) Rezago socioeconómico. Pese a que Juárez domina la economía y la demografía en Chihuahua, se caracteriza por altos índices de polarización social, exclusión 
educativa y extrema pobreza. Existe a su vez un tremendo déficit habitacional y de desarrollo urbano, y elevados niveles de drogadicción y prostitución. Alrededor de 120000 jóvenes de entre 15 y 26 años no tienen acceso al aparato escolar ni al mercado laboral, situación que parece ser un campo abonado para el surgimiento de los denominados Ninis.

c) Baja calidad de vida y desarrollo humano. El número de colonias afectadas por la violencia y el crimen en Ciudad Juárez ha aumentado gradualmente en los últimos diez años. En este sentido, catorce puntos críticos han sido identificados con más altos niveles de crimen y violencia. No es mera coincidencia que en estas zonas se encuentren las colonias con las calificaciones más bajas en los indicadores de vivienda e infraestructura de servicios públicos. Además, en estas colonias se constata también la mayor carencia de escuelas, de instituciones de educación media superior y de áreas verdes y recreativas.

d) Alta concentración de pandillas Se estima que en Juárez existen cerca de quinientas pandillas con una membresía total aproximada que fluctúa entre las 15000 y 25000 personas. Treinta pandillas son consideradas de alta peligrosidad por su actuación extremadamente violenta. Entre estas destacan: Barrio Azteca, Los Mexicles, Los Bufones, Los Artistas Asesinos, Killer 13, Los Lobos, Los Veteranos, La Quinta y Los Diablos. Cientos de pequeñas pandillas barriales fueron absorbidas por pandillas más grandes, que a su vez fueron reclutadas como asesinos a sueldo por grandes cárteles. En algunos casos a los jóvenes se les paga mil pesos mexicanos (78 dólares) por cada ejecución (ICC, 2013:15). Particularmente, Barrio Azteca y Los Mexicles, las pandillas más poderosas, mantienen alianzas con los cárteles de Juárez y Sinaloa, respectivamente. De tal suerte que, las pandillas sacaron la violencia de la clandestinidad pues, a medida que se intensificaban los conflictos territoriales, los miembros de las pandillas y sus potentes armas se hicieron más visibles.

e) Ineficacia policial. Históricamente, la alta presencia policial que registra Ciudad Juárez no ha podido frenar el ímpetu de la violencia criminal. En 2010, el municipio contaba con 4,3 policías federales por cada mil personas, estadística muy por encima del promedio de 2,8 policías por cada mil habitantes recomendado por Naciones Unidas. Pese a ello, estaba controlada por el narco mediante la corrupción y amenazas a sus agentes. Al tener que decidir entre estar en la nómina de carteles o morir, y sin el apoyo de sus superiores, los oficiales de policía ya no protegían a las personas frente al crimen (Guerrero, 2010).

\section{¿CAMBIO DE ESTRATEGIA?}

Particularmente, la violencia asociada al narcotráfico en Juárez alcanzó su punto más alto en 2008, después de que el Cártel de Sinaloa, el Cártel de Juárez y sus respectivos servidores declararon una guerra abierta contra el otro, con Juárez como punto 
focal del enfrentamiento al ser la franja fronteriza por la que entra más droga a Estados Unidos. En ese momento, la tasa de homicidios fue de 130 por cada 100000 habitantes, lo cual representa un 35\% de los asesinatos a nivel nacional (Pachico, 2013). A causa de estos niveles de violencia, el gobernador José Reyes Baeza y al alcalde, José Reyes Ferriz, solicitaron una intervención federal. De esa manera, el 21 de marzo 2008, el exsecretario de Gobernación, Juan Camilo Mouriño, anunció el inicio del Operativo Conjunto Chihuahua. En la primera fase del operativo se desplegaron 2026 efectivos militares junto a 425 agentes de la Policía federal y Procuraduría General de la República (PGR). Tan solo cinco días después los militares asumieron el control de las instalaciones y funciones policiales en el estado de Chihuahua. En junio del mismo año, el Gobierno federal ordenó el despliegue de otros 1400 soldados para apoyar a los que ya estaban operando en Chihuahua. En marzo de 2009, el Gobierno anunció que iba a enviar 5332 soldados más a Ciudad Juárez y las fuerzas armadas tomaron el control de la policía local (Medellín, 2009).

Como en otras zonas del país, la ofensiva militar llevó a un contragolpe criminal y a una escalada de violencia sin precedentes pues, a pesar de la presencia masiva de militares en Chihuahua durante más de dos años, especialmente en Ciudad Juárez, los niveles de violencia delictiva no decayeron; por el contrario, entre 2006 y 2009 se cometieron alrededor de 4500 ejecuciones, es decir, tan solo en tres años el número de asesinatos en esa localidad creció quince veces (ICC, 2015: 1). No obstante, las autoridades federales y subnacionales se recriminaron mutuamente por la escalada de violencia y la cooperación inicial se quebró.

Un horrible acontecimiento provocó un vuelco inesperado en la estrategia trazada originalmente por el Gobierno federal para esta convulsionada capital norteña. Villas de Salvárcar, ubicada al sur de Juárez, es un barrio obrero de pequeñas casas subsidiadas por el Gobierno que alberga a los trabajadores de las maquilas y sus familias. El 30 de enero de 2010, un grupo de jóvenes deportistas tenía una celebración en una de las casas que fueron abandonadas como consecuencia de la crisis subprime de 2008. Poco antes de la medianoche, una docena de hombres con armas de asalto irrumpieron en la vivienda dejando un saldo de dieciséis muertos.

Si bien antes de esta masacre existía una creciente preocupación por los altos niveles de violencia, que se manifestaba mediante protestas contra la presencia militar, esta tragedia en particular causó indignación local y nacional pues simbolizaba no solo la brutalidad de los sicarios, sino también la incompetencia y negligencia de las autoridades locales. Los juarenses no lograban entender cómo un grupo de «hombres fuertemente armados habían podido cometer un asesinato en masa y luego desaparecer en una ciudad bajo ocupación militar, con numerosos retenes. Aunque había un puesto médico y policial a pocas cuadras, el personal de emergencia y policía tardaron más de media hora en llegar, a pesar de las repetidas llamadas de auxilio» (ICC, 2015: 8).

A ello se sumó el mal manejo comunicacional demostrado por el expresidente Calderón, quien en varias ocasiones había calificado las muertes de civiles como un «daño colateral en la Guerra contra el narcotráfico». Así, durante una rueda de prensa en Tokio reaccionó frente a la muerte de los dieciséis adolescentes sugiriendo que las 
víctimas eran pandilleros, al afirmar que "probablemente fueron asesinados por otro grupo con el que tenían cierta rivalidad» (EFE, 2010); es decir, un caso más de se matan entre ellos. Lo primero que se dio a conocer tras el crimen fue que La Línea (brazo armado del Cártel de Juárez) tenía órdenes de acabar con miembros de la pandilla Artistas Asesinos, que a su vez operaban con un cártel competidor, el de Sinaloa. No obstante, las investigaciones demostraron que los jóvenes asesinados no tenían ningún nexo con el crimen organizado. Por lo tanto, Calderón los criminalizó sin citar ninguna fuente que pudiera corroborar su hipótesis, la cual después retiró rápidamente. Esas desafortunadas declaraciones generaron una ola de críticas en la comunidad juarense contra el Gobierno, expresándolas en la visita de Calderón a los pocos días de ocurrida la matanza.

Si bien al comienzo Calderón hizo oídos sordos a los llamados a desmilitarizar Ciudad Juárez, el exmandatario debió retroceder en su política original y cambió su discurso en materia de seguridad, reconociendo la imperiosa necesidad de reformular la intervención federal mediante la implementación de una política integral orientada a minar, desde las raíces, la penetración del narcotráfico y la violencia que se vivía en el otrora Paso del Norte: «Necesitamos un enfoque más integrado [...] que incluya iniciativas de naturaleza social». De ese modo, el mismo presidente, quien en 2006 había anunciado su ofensiva contra cárteles vestido con una chamarra verde olivo, ahora admitía que «la acción militar no es suficiente por sí sola» (Wilkinson, 2010).

Precisamente, Ciudad Juárez era un símbolo visible del enfoque aplicado durante la guerra contra el narcotráfico, basado fundamentalmente en la ocupación policiaco-militar. Juárez era una plaza ocupada permanentemente con miles de efectivos desde el Operativo Conjunto Chihuahua en 2008. Nadie podía negar que en Ciudad Juárez, como en ningún otro sitio, se ejecutara a cabalidad y plenitud la visión, diagnóstico y estrategia originalmente concebida por el expresidente panista. Como plantea Lorenzo Córdova, académico del Instituto de Investigaciones Jurídicas de la UNAM, el principal error cometido por la administración Calderón radicó justamente en su «visión unidimensional sobre seguridad pública. [Entendieron] el problema desde una perspectiva netamente policiaca y, en consecuencia, las políticas públicas al respecto [respondieron] a esa lógica. Pero en realidad el tema [poseía] una dimensión múltiple: existen factores sociales y económicos que inevitablemente inciden e influyen en el fenómeno de la delincuencia organizada, pero [fueron] descuidados y olvidados desde el punto de vista de la política pública» (Olivares, 2009).

\section{¿EN QUÉ CONSISTIÓ TSJ?}

En respuesta a la creciente presión pública, el exmandatario panista había ordenado a su equipo que diseñara una estrategia social para complementar los despliegues militares. El objetivo era crear un modelo de intervención que pudiera expandirse a todo el país. De hecho, hacia fines de 2009, expertos de seis secretarías llevaban meses trabajando en un plan de rescate para Juárez, con proyectos para mejorar los espacios 
públicos, ampliar el acceso a la educación y promover la salud, incluido el tratamiento de la drogadicción. No obstante, la ola nacional de ira y frustración que causó la masacre de Villas de Salvárcar colocó al Gobierno federal en una posición políticamente más vulnerable y, con ello, forzó a imprimirle mayor sentido de urgencia en su actuación.

Felipe Calderón, acompañado por siete secretarios de Estado y por el titular de la PGR, emprendió tres viajes a Juárez a lo largo de un mes. Como resultado de estas visitas, el Gobierno federal anunció el 17 de febrero de 2010 la iniciativa TSJ con el objetivo de reducir la violencia desatada en la ciudad fronteriza mediante la reconstrucción del tejido social. Este programa integral, que requería una inversión aproximada de cincuenta millones de dólares, contemplaba la utilización de todo el conjunto de herramientas a disposición del Estado para abordar la problemática de la seguridad en Juárez. Se concibió como una ambiciosa intervención social que incluía la expansión de la infraestructura pública, transporte, guarderías y oportunidades culturales para la comunidad.

Según la hoja informativa del proyecto, el Gobierno federal plantea que la inseguridad, la falta de oportunidades sociales y económicas, la descomposición del tejido social y la proliferación de conductas antisociales son fenómenos entrelazados que no permiten el desarrollo pleno de los juarenses. Por ello, TSJ atiende el problema de forma integral, atacando no solo los efectos sino también las causas de la violencia (Muggah y Szabó de Carvalho, 2016: 33-34). Se estima que aproximadamente tres cuartas partes de los recursos (74\%) se destinaros a salud pública y educación, y a programas de fomento de la cultura, el deporte y el desarrollo. En contraste, tan solo una cuarta parte de las partidas se dirigió al ítem seguridad, como la instalación de dispositivos de seguimiento por satélite en vehículos policiales, más investigadores especializados en extorsión o secuestro, y asesores de crisis para víctimas (véase el gráfico 1).

\section{GrÁfICO 1.}

DistribuCIÓN DE LA INVERSIÓN FEDERAL TOTAL POR ÁREA DE POLÍTICA PÚbLICA (2OIO-2OII)

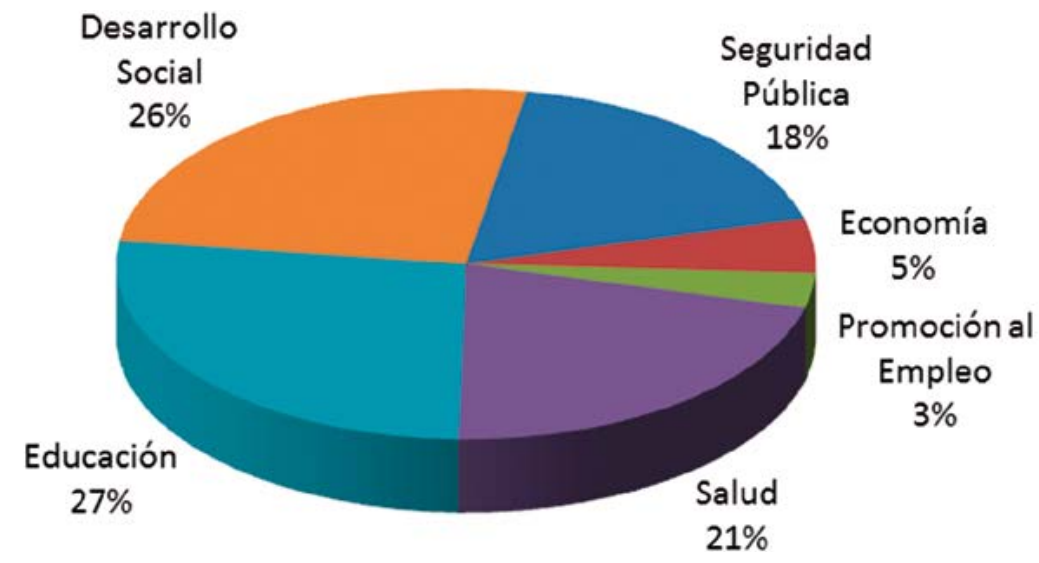

Fuente: elaboración propia a partir de Calderón (2013). 
Dicho de otra forma, la mayoría de los recursos fueron dedicados a inversión social o, alternativamente, a proyectos de prevención social de la violencia. Bajo esa lógica, cabe destacar que el volumen de inversión en Juárez fue muy significativo considerando que, en años posteriores, el presupuesto federal de prevención de la violencia para todo México ascendió a menos de 3000 millones de pesos, es decir, menos de lo que había sido gastado en Juárez entre 2010 y 2011. Igualmente, la declaración de Juárez como «emergencia nacional» ayudó a simplificar los procedimientos administrativos y a agilizar las inversiones. En suma, toda esa inversión venía a compensar una percepción de abandono histórico de la ciudad por parte de los Gobiernos federales y estatales.

Aunque el expresidente no tuvo en cuenta a los Gobiernos estatal y local en el desarrollo de las primeras fases de TSJ, la creciente presión de la sociedad civil obligó al Gobierno federal a cooperar con las autoridades subnacionales en la ejecución del programa y a considerar también la voz de los juarenses, pues constituían la población objetivo, en tanto podían influir mayormente en ella. De este modo, académicos, organizaciones no gubernamentales, empresarios, trabajadores y dirigentes comunitarios formaron parte fundamental de la formulación, implementación y seguimiento de este proyecto, que contempló ciento sesenta compromisos para cumplir en 2012, agrupados en cinco categorías: seguridad, economía, empleo, salud, educación-cultura y desarrollo social (véase la tabla 1). El cumplimiento de estos compromisos fue vigilado por mesas ciudadanas, cuestión fundamental en el éxito de TSJ.

TABLA 1.

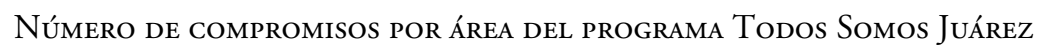

\begin{tabular}{lc}
\hline \multicolumn{1}{c}{ Área de política pública } & Número de compromisos \\
\hline Seguridad & 12 \\
\hline Economía & 11 \\
\hline Empleo & 5 \\
\hline Salud & 40 \\
\hline Educación-Cultura & 72 \\
\hline Desarrollo Social & 20 \\
\hline Total & $\mathbf{1 6 0}$ \\
\hline
\end{tabular}

Fuente: elaboración propia a partir de Calderón (2013).

Los objetivos generales de la estrategia implementada en 2010 por el Gobierno del expresidente Felipe Calderón fueron los siguientes:

- combatir las causas que generan la violencia;

- recuperar la paz y tranquilidad de los habitantes de la ciudad mediante la restauración del orden público;

- generar lazos de confianza entre los juarenses para reconstruir el tejido social. 
Por otra parte, los objetivos específicos fueron los siguientes:

- establecer una comunicación directa con las autoridades para tratar asuntos en materia de seguridad;

- atender, promover y generar propuestas de proyectos e ideas que tengan como objetivo disminuir la delincuencia y promover la cultura de la legalidad;

- promover la confianza entre sociedad y autoridades con base en hechos;

- informar verazmente a la comunidad sobre el resultado de los indicadores de seguridad y su análisis;

- fortalecer las instituciones de seguridad municipales, estatales y federales;

- garantizar la permanencia y continuidad de programas y proyectos de seguridad, más allá de la culminación de las diferentes administraciones;

- reconocimiento institucional de la mesa por las tres esferas gubernamentales.

La sociedad civil se organizó y, junto a los tres niveles de gobierno (municipal, estatal y federal), se creó un canal de diálogo permanente con la Mesa de Seguridad y Justicia, con reuniones periódicas para discutir los avances y obstáculos de la seguridad juarense. El principal objetivo de la mesa consiste en reducir las tasas de criminalidad, de la que hace un seguimiento mensual mediante seis indicadores: número de homicidios, robos de vehículos con y sin violencia, secuestro, extorsión y robos a comercios. Sin embargo, el grupo no solo observa el comportamiento delictual: «La Mesa no tiene autoridad formal [...], pero actúa como un órgano ejecutivo: se llega a acuerdos, alguien se hace responsable [...] y en la siguiente reunión se evalúa el progreso» (ICC, 2015: 22).

Cabe subrayar que la mesa es autónoma y voluntaria y está integrada por catorce organizaciones, entre ellas asociaciones empresariales, grupos profesionales, la comisión de derechos humanos, una asociación de jóvenes y la universidad local. Si bien recibió críticas por no ser plenamente representativa, sus miembros afirman que se esfuerza por ser inclusiva y fomentar la expresión de diversos puntos de vista. La mesa se reúne dos veces cada mes, en sesiones plenarias con autoridades municipales, federales y estatales, incluido el alcalde, los jefes de la policía municipal y de tránsito, los comandantes locales de policía estatal y federal, y el fiscal del distrito de Juárez. Igualmente, conviene puntualizar que en dicha instancia se conformaron las siguientes comisiones: Centro de Atención Inmediata; Corredores de Seguros; Cultura de Legalidad; Identificación de Autos; Denuncias de Incidentes en Centros de Entretenimiento; Inteligencia Ciudadana; Sistema de Indicadores; Secuestro y Extorsión; Comunicación y Difusión, y Grupo de Participación con PGR (Milo, 2011).

A partir de lo anterior, es posible afirmar que la ejecución de Todos Somos Juárez estuvo fundamentada en los siguientes pilares:

- Participación ciudadana. Son los mismos ciudadanos juarenses quienes conocen mejor su realidad, por lo que, organizados en mesas de trabajo, fueron convocados para dar sus impresiones y así poderse elaborar una solución más efectiva de esta problemática. Fueron las recomendaciones realizadas por estas mesas las que 
sirvieron como insumos o inputs de los ciento sesenta compromisos gubernamentales y también las que definieron a los representantes ciudadanos que vigilarían el cumplimiento de los objetivos trazados.

- Integralidad de las políticas públicas. La complejidad de la situación vivida en Juárez ameritaba que la política pública diseñada para solucionar el problema fuera una estrategia que articulara distintas instituciones y áreas de gestión pública.

- Corresponsabilidad y participación de los tres niveles de gobierno, que se materializa en el trabajo de dependencias y secretarías federales junto a entes municipales y estatales para asegurar el alto impacto de TSJ.

\section{¿CUÁLES FUERON LOS RESULTADOS?}

Según Calderón (2013), el Gobierno federal invirtió más de 283 millones de dólares en TSJ, consiguiendo notables avances, entre los que cabe destacar:

- un millar de escuelas se incorporaron al programa Escuelas Seguras, que promueve un ambiente seguro a través de la prevención de la drogadicción y la violencia;

- el número de becas también aumentó de manera espectacular, y la infraestructura educacional mejoró, especialmente en partes previamente desatendidas. Se otorgaron 14552 nuevas becas a estudiantes secundarios y universitarios, lo que equivale a más de diez veces las concedidas en 2010. Además, se mejoró la infraestructura básica de doscientas cinco escuelas y se construyeron cinco nuevas escuelas preparatorias y una universidad;

- se dio cobertura universal de salud a través de la afiliación de más de 341000 familias al Seguro Popular, programa gratuito del Gobierno federal de seguro médico. Cuatro grandes centros de salud fueron construidos y uno remodelado, incluyendo el Hospital Infantil y la conclusión del Hospital Psiquiátrico;

- se concedieron créditos blandos a 1379 pequeñas y medianas empresas, lo que permitió la creación de 835 empleos y la preservación de 18073 puestos de trabajo. Además, 10240 solicitantes de empleo han recibido becas de capacitación;

- se incorporaron más de catorce mil familias al programa federal contra la pobreza Oportunidades, llegando así a más de veinticinco mil familias. Se hizo otorgando subsidios en efectivo a hogares vulnerables, condicionados a que inscriban a sus hijos en la escuela y los lleven a chequeos médicos regulares.

En paralelo, los principales índices de criminalidad mostraron claras mejorías. Como se mencionó con anterioridad, se decidió priorizar la atención en seis delitos: homicidios, robos de vehículos con y sin violencia, secuestro, extorsión (cobro para el derecho a piso), y robos a comercios. Los gráficos que se incluyen a continuación son aportados por la Mesa de Seguridad y Justicia, con datos que comprenden desde el mes previo a la puesta en marcha de TSJ, enero de 2010, a diciembre de 2012. Cabe aclarar que el marco temporal obedece a que, si bien la administración sucesora, Peña 
Nieto (2012-2018), continuó algunas de las políticas, no se apropió del programa TSJ en su totalidad.

Y aunque la intervención no estuvo dirigida única ni exclusivamente a los homicidios, todos los actores involucrados en el proyecto consideraban la reducción de los homicidios como la primera meta, tanto por su importancia en sí como por su vinculación con otros delitos. Como puede apreciarse, la cantidad de homicidios diarios se redujo dramáticamente, pasando de 9,9 en 2010 a tan solo dos en 2012.

GráfICO 2.

Homicidios diarios en CiUdAd Jú́rez (2007-20I2)

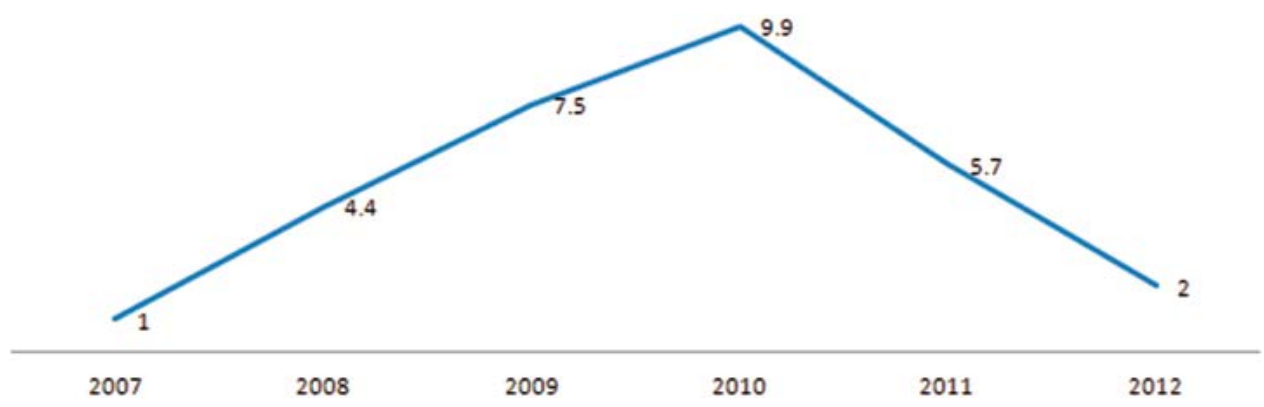

Fuente: elaboración propia a partir de Pachico (2013).

Del mismo modo, en el gráfico 3 se aprecia que la tasa de homicidios en diciembre de 2012 cayó un $90 \%$ en relación con el mes más violento desde el inicio de TSJ (enero de 2011 con 269). En esa línea, la tasa de homicidios por cada cien mil habitantes disminuyó en forma notable, pasando de 145 en enero de 2010 a tan solo veintiocho en diciembre de 2012, como se observa en el gráfico 4.

Gráfico 3.

EvoluCIÓN DE HOMICIDOS EN CIUdAd JuÁREZ (2OIO-2OI2)

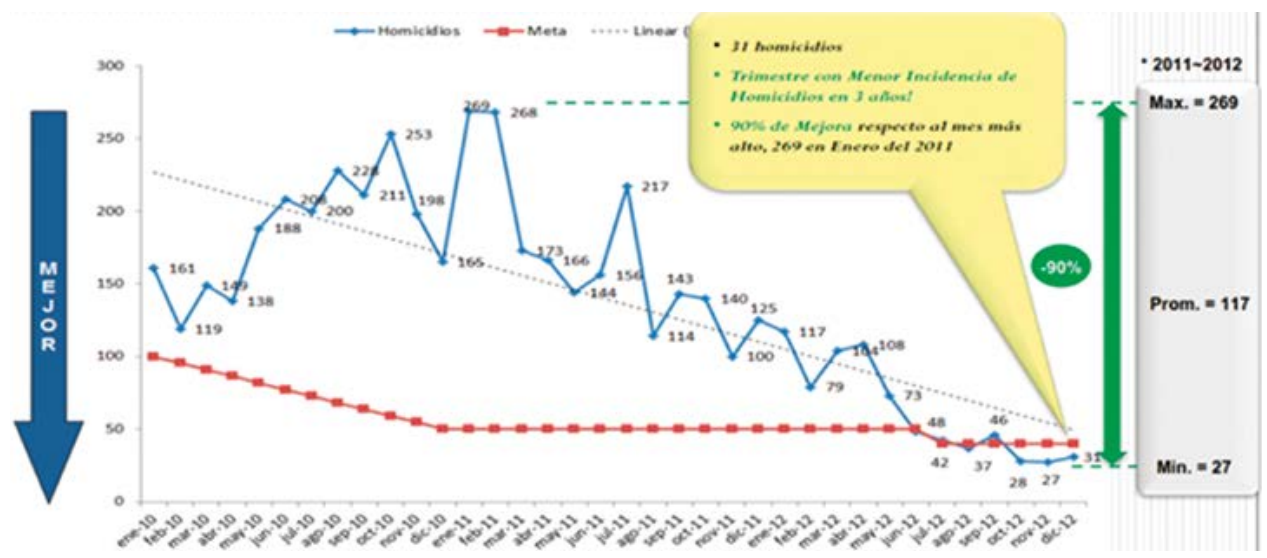

Fuente: Mesa de Seguridad (2012: 6). 
GráFICO 4.

EVOLUCIÓN DE LA TASA DE HOMICIDIOS CADA CIEN MIL HABITANTES EN CIUDAD JUÁREZ (2OIO-2OI2)

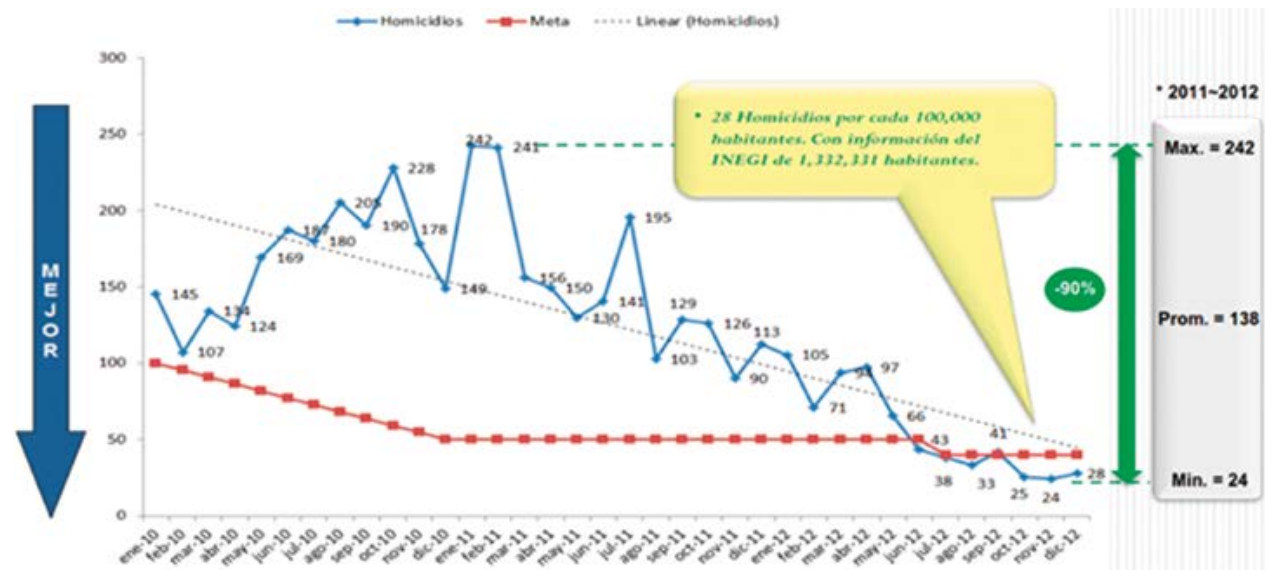

Fuente: Mesa de Seguridad (2012: 7).

Además, Juárez ha logrado un éxito notable en la disminución de otros indicadores delictivos. Por ejemplo, el robo de autos con violencia y sin violencia está cercano a los niveles presupuestados como meta para el tiempo límite y la disminución en el tiempo ha sido significativa. Como se aprecia en el gráfico 5, desde enero de 2011 a diciembre de 2012 se registró una caída del $88 \%$ en el robo de vehículos, y el robo a mano armada en negocios comerciales decreció en um $75 \%$ entre mayo de 2011 y diciembre de 2012 (véase el gráfico 7).

Gráfico 5.

Evolución del robo de autos CON violencia en Ciudad JuÁrez (2OIO-2OI2)

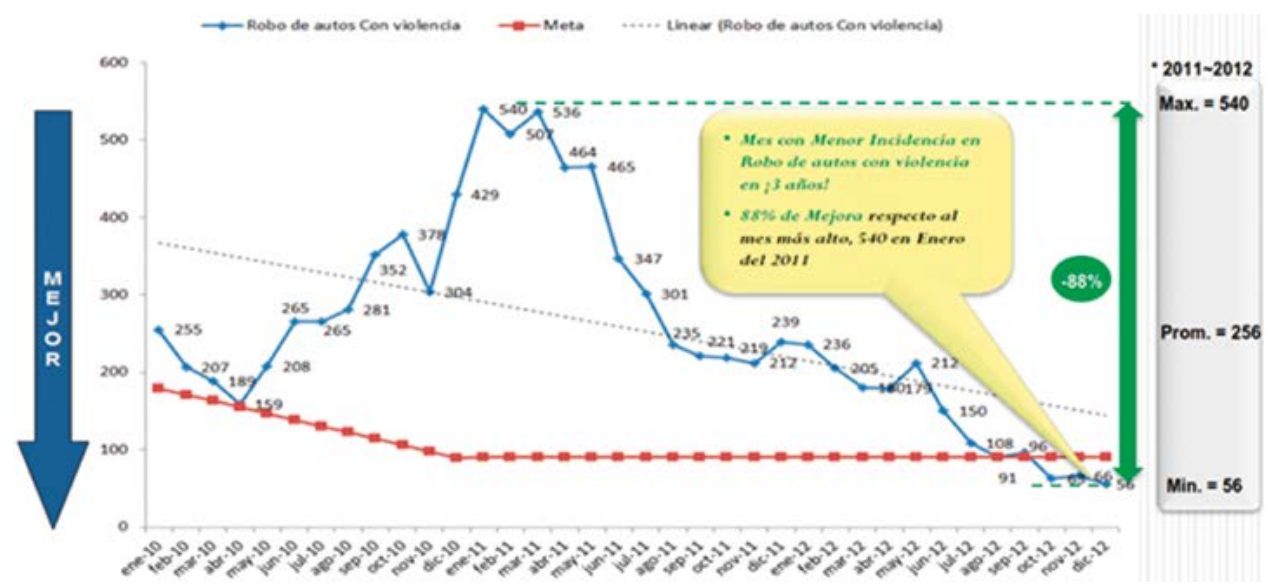

Fuente: Mesa de Seguridad (2012: 8). 
GrÁFICO 6.

EvoluCión DEL ROBo DE AUTOS SIN VIOLENCIA EN CIUDAD JuÁREZ (2OIO-2OI2)

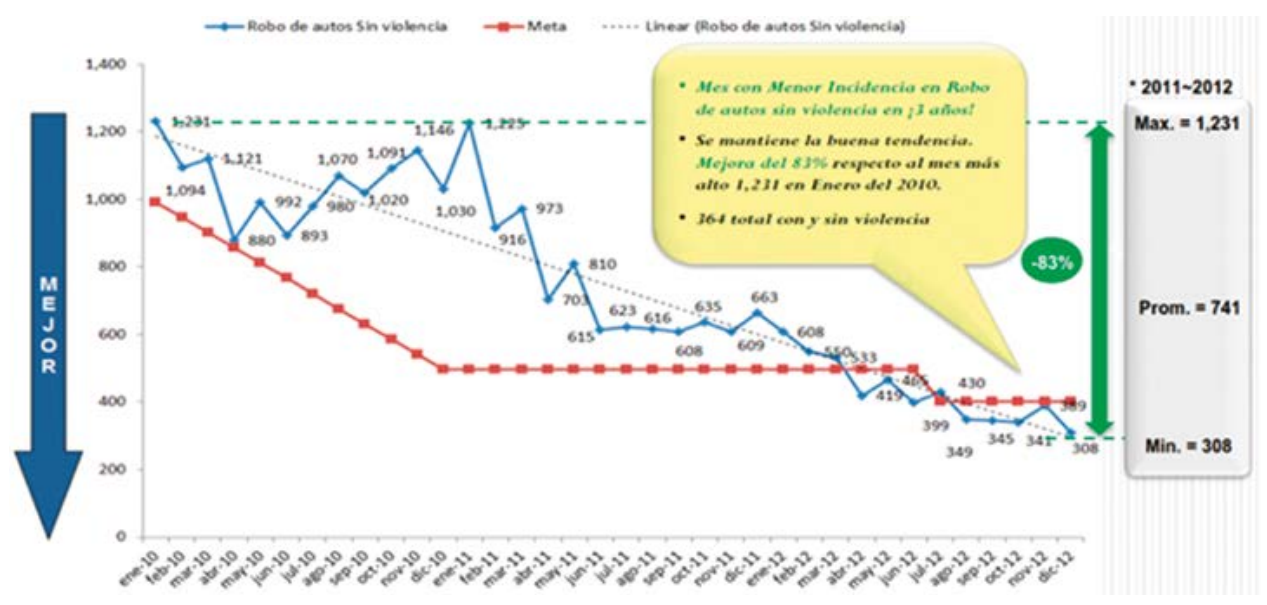

Fuente: Mesa de Seguridad (2012: 9).

Gráfico 7.

Evolución del robo en comercios con violencia en Ciudad Juárez (2OIO-2OI2)

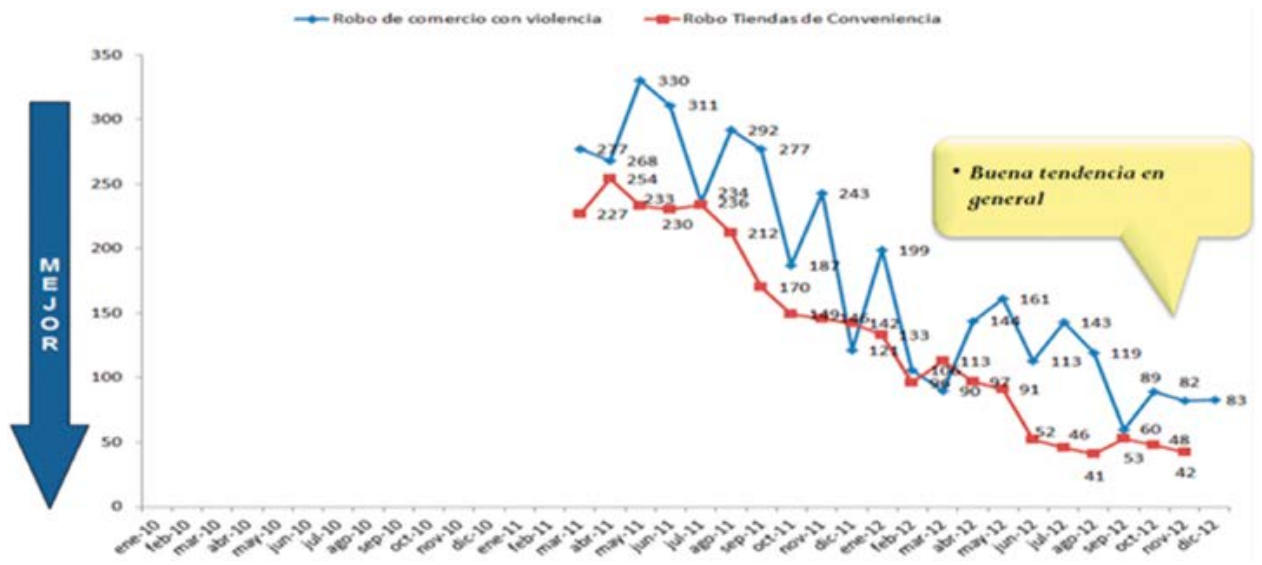

Fuente: Mesa de Seguridad (2012: 10).

Si bien no logró cumplirse completamente la meta en relación con la extorsión, también las denuncias por este delito disminuyeron considerablemente (véase el gráfico 8). Además, como se observa en el gráfico 9, Ciudad Juárez consiguió apartarse de la tendencia nacional en índices como el número de secuestros: en diciembre de 2012 aumentó cerca de un $20 \%$ en todo el país, mientras que en Juárez disminuyó un $100 \%$, o sea, no se informó sobre ningún secuestro. 
GráFICO 8.

EvoluCión de LAS DENUNCIAS DE EXTORSIÓN (COBRO DE PISO) EN CIUDAD JuÁREZ (2OIO-2OI2)

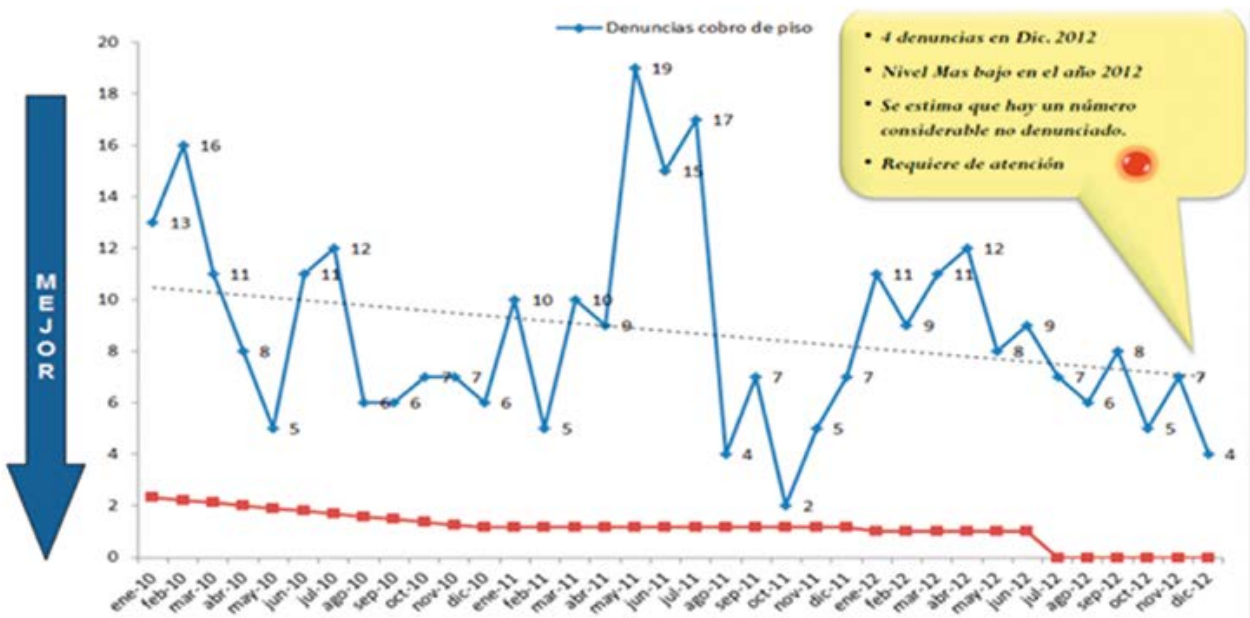

Fuente: Mesa de Seguridad (2012: 11).

GráFICO 9.

Evolución de denuncias por Secuestro en Ciudad JuÁrez (20IO-2OI2)

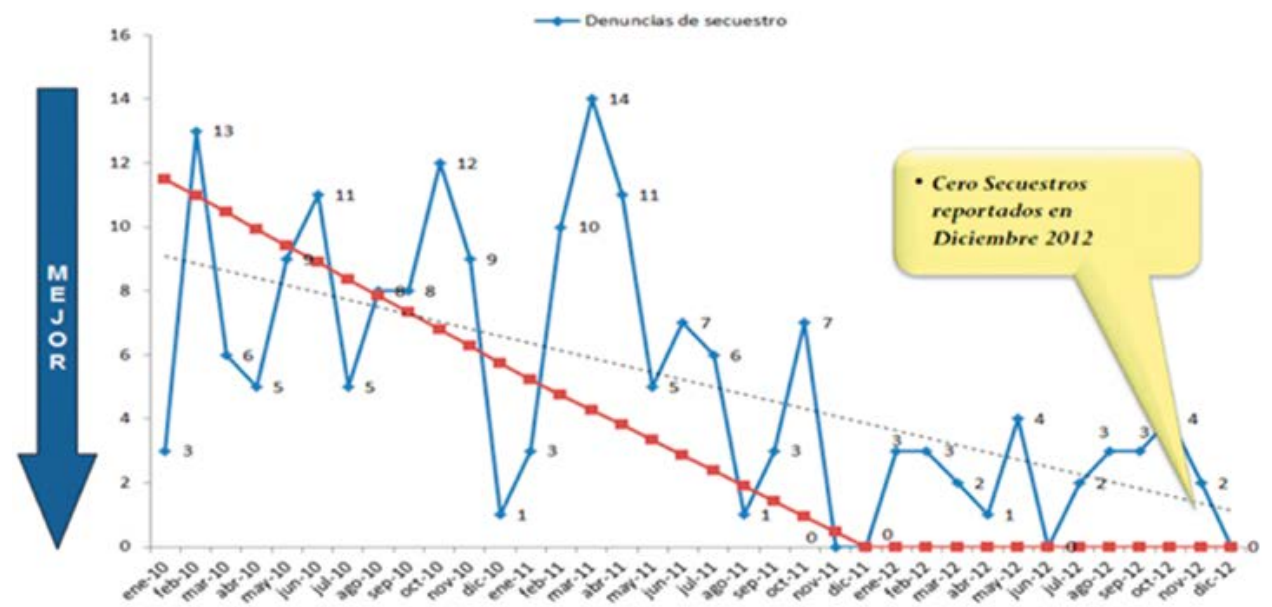

Fuente: Mesa de Seguridad (2012: 12).

Estos datos reflejan el cambio de tendencia originado por la inclusión de la perspectiva ciudadana y una aproximación integral de las políticas destinadas a Ciudad Juárez, llegando a cumplirse gran parte de las metas propuestas por la Mesa de Seguridad y Justicia. Así, TSJ se convirtió en el mayor triunfo de la administración 
calderonista en materia de seguridad. En efecto, Calderón (2012) decía en febrero de 2012: «El trayecto aún es largo; los desafíos, enormes. Hoy, el rostro y la realidad de Ciudad Juárez están cambiando, poco a poco estamos superando injusticias y abatiendo rezagos añejos; $y$, gracias al esfuerzo de los juarenses, hoy comienza a clarear el horizonte [...]. Hoy, más que nunca, Todos Somos Juárez».

Pese a que existe consenso sobre el desenlace final, la reducción de la violencia, han surgido una gran variedad de hipótesis sobre los factores que incidieron en el resultado. En ausencia de una evaluación oficial del impacto, es natural que las interpretaciones sobre un proceso tan complejo y con tantas dimensiones diverjan en función de los actores. Sin embargo, es posible identificar algunos elementos de las políticas de Calderón que pudieron haber ayudado a que la crítica situación en Ciudad Juárez cambiara de rumbo.

En primer lugar, según International Crisis Group (2015), TSJ en tanto política pública significó una cuantiosa inyección de recursos provenientes del nivel federal, dando oportunidades a la juventud en riesgo para ayudarle a evitar la tentación de entrar a formar parte de las pandillas callejeras. En palabras de Sandra Ramírez, trabajadora del proyecto comunitario no gubernamental Plan Estratégico de Juárez: «De repente hubo una cascada de financiamiento para programas como nunca habíamos visto». Desde ese ángulo, cabe destacar que: «El Gobierno de Juárez emprendió una campaña sin precedentes para crear centros comunitarios, especialmente en las zonas más desfavorecidas, aumentando su número de doce, en octubre 2010, a 44 para fines de 2012. Estos centros tienen como objetivo ganarse los corazones y las mentes de los residentes y alejarlos de los cárteles, ofreciendo programas de desarrollo personal, instalaciones deportivas y esquemas para la reconstrucción de barrios. Gran parte del dinero para su construcción fue proporcionado por el Gobierno federal, a través de Secretaría de Desarrollo Social» (ICC, 2015:14).

En segundo lugar, antes de anunciar su intención de poner más énfasis en la inversión social mediante TSJ, en enero de 2010 el Gobierno federal declaró que efectuaría un cambio en su estrategia de seguridad: el repliegue gradual del ejército junto al traspaso del control del Operativo Conjunto Chihuahua a la Policía federal, bajo el nuevo nombre de Operación Coordinada Chihuahua. En abril de 2010, aproximadamente 5000 policías federales fueron enviados para sustituir a los militares en la ciudad, con el apoyo de 3000 policías municipales (Stevenson, 2010). Tras su llegada, la Policía federal prometió implementar tácticas más sofisticadas, en contraste con las operaciones agresivas que habían caracterizado al Ejército (ver Gráfico 10). En diciembre de 2011 Juárez vio la retirada total de militares y de la mayoría de policías federales distribuidos en la ciudad, y el retorno de la autoridad a las unidades de la policía local. La entrega tuvo mucho que ver con la insatisfacción pública con los soldados, fuertemente criticados por cometer abusos y contribuir negativamente a la época más violenta de la ciudad, así como con su inefectividad en disminuir la violencia y criminalidad. Los militares que patrullaban las calles en Juárez tenían poca capacidad de inteligencia y escaso conocimiento de la ciudad y su dinámica criminal. Por tal motivo, los militares no solo usaron desproporcionadamente la fuerza, sino también 
cometieron violaciones al Estado de derecho, como irrumpir en las casas sin una orden judicial (Felbab-Brown, 2011b).

\section{Gráfico 10.}

Evolución de homicidios e intervención de fuerzas federales en CiUdad JuáreZ (2007-20II)

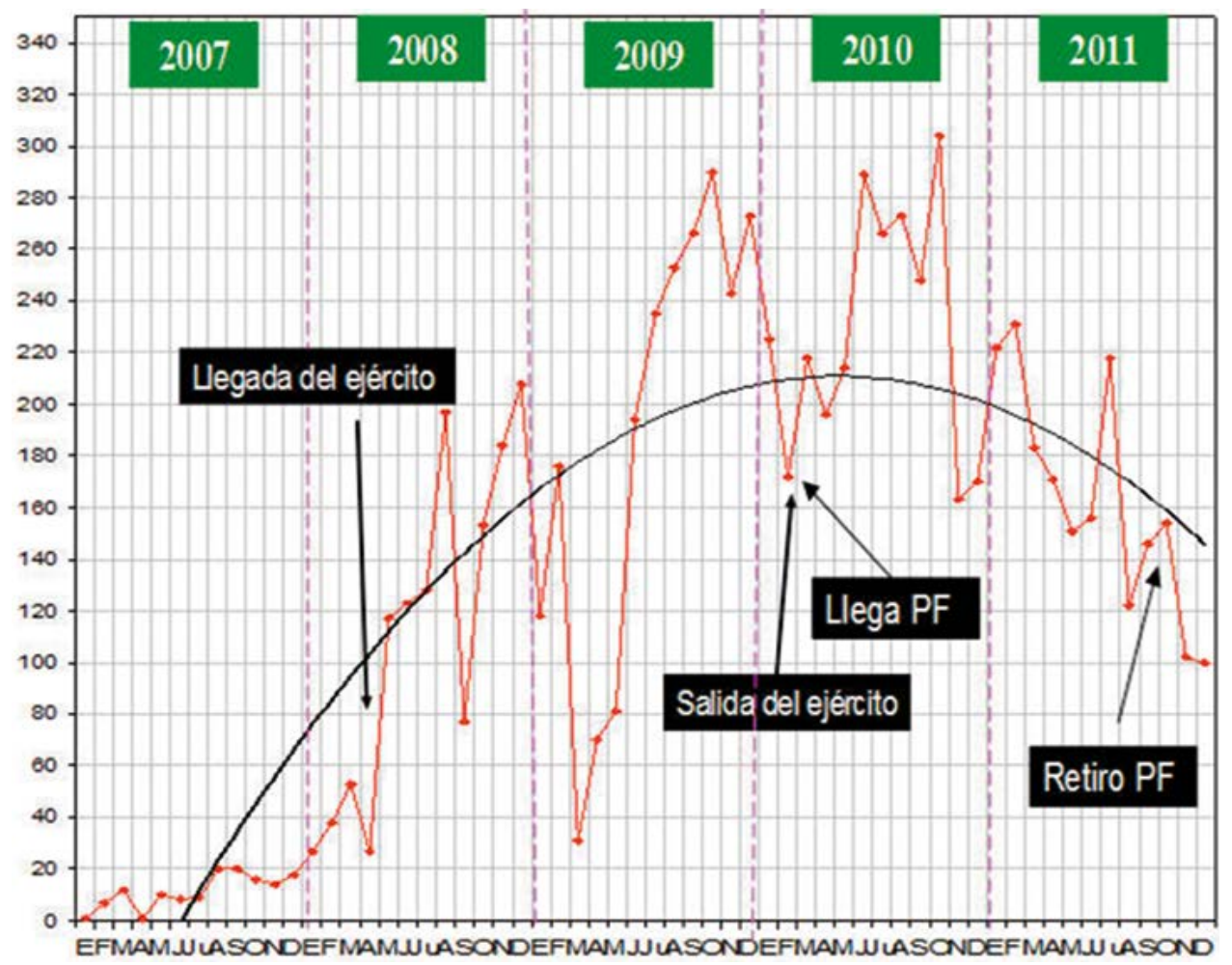

Fuente: Escobar (2012).

Vinculado a lo anterior, se encuentra la reconstrucción de la Policía municipal bajo el liderazgo de Julián Leyzaola, un coronel retirado del Ejército que en marzo de 2011 tomó las riendas como secretario de Seguridad Pública de Juárez, después de haber liderado un cambio brutal pero efectivo en Tijuana. De esa manera, el exmilitar no reemplazó a los oficiales de policía por soldados como sucedió en Guadalupe, Nuevo León (Corcoran, 2011). En su lugar, la Policía municipal fue completamente limpiada, más de la mitad de los agentes y oficiales fueron despedidos o renunciaron. O sea, la primera medida del Gobierno federal en Juárez, aniquilar la Policía, fue correcta desde el punto de vista jurídico. Cambiaron a tres mil policías por dieciséis mil agentes entre soldados y agentes federales. Sin duda, aquellos tres mil policías estaban corrompidos por los narcos porque era la única forma de sobrevivir en ese ambiente 
(Petersen, 2010). En efecto, desde la llegada de Leyzaola más del $90 \%$ de las fuerzas de seguridad estatal y municipal en Chihuahua han sido certificadas tras haber aprobado la verificación de sus antecedentes y pruebas poligráficas (Chaparro, 2013). Igualmente, el exmilitar incitó a la fuerza de seguridad local a asumir un papel mucho más activo en el combate contra el crimen, ejecutando métodos policiales en sintonía con la teoría de Ventanas Rotas ${ }^{2}$ desarrollada en Nueva York: creó bases de datos de delincuencia por vecindarios y desplegó a sus elementos para atacar delitos en áreas específicas en función de esas estadísticas.

En noviembre de 2010, la Secretaría de Seguridad Pública juarense dio a conocer la puesta en marcha de una nueva política para el control total de las calles: la construcción de islas de seguridad, un programa que divide la ciudad en secciones, y que visualiza a la ciudad como una serie de bloques o cuadrantes, cada uno con un policía asignado para proteger un área específica. Por lo tanto, esta iniciativa se centró en reducir los niveles de delincuencia sección por sección, ocupando los barrios más peligrosos con agentes policiales (Chaparro, 2013). No obstante, este cambio no estuvo exento de efectos secundarios: el número de residentes encarcelados se disparó, y se recibieron denuncias de abuso por parte de fuerza policial municipal. Más aún, desde su llegada las quejas se triplicaron (Camarena, 2012).

Sin embargo, actualmente la policía juarense «comete muchos menos abusos que sus antecesores infiltrados por el crimen organizado, según los residentes. El actual jefe, César Muñoz, dice que fortalecer las relaciones comunitarias es su máxima prioridad: los agentes visitan las escuelas frecuentemente y se les alienta a hablar con los residentes en lugar de permanecer en sus vehículos» (ICC, 2015: 14). Por lo demás, la dirección de Leyzaola contribuyó a mejorar la seguridad y dificultó las operaciones de los cárteles y sus soldados. Respaldado por estos favorables resultados, Leyzaola insistió en que podía hacerse cargo de la seguridad pública empleando únicamente a la policía municipal.

En quinto lugar, la crisis impulsó reformas orientadas al fortalecimiento institucional de los Gobiernos estatal y municipal mediante medidas legislativas y administrativas en el sector de la seguridad y la justicia. Bajo esa premisa, el código penal estatal fue endurecido; entre otras cosas, se estableció la sentencia máxima de cadena perpetua para los delitos de secuestro, extorsión, homicidios múltiples y el asesinato de policías o periodistas. Se purgó a fiscales del Estado, y se investigaron periódicamente sus antecedentes; además se mejoraron su formación y condiciones laborales. "Antes, los malos estaban tanto fuera como dentro. La Fiscalía estaba infiltrada», indica un fiscal de Juárez. Vale decir, la mayoría de mandos policiales estaban en la nómina de los cárteles, y que trabajar para el narco no era una opción, sino un

2. Postulado que busca aplicar medidas desde el momento en que surgen los primeros indicios de disfunción social, de forma que no se dé oportunidad al deterioro del clima social. No obstante, la eficacia de estos enfoques ha sido ampliamente cuestionada, sobre todo en el momento de su aplicación en el contexto latinoamericano (Lohmuller, 2015). 
imperativo. «O entrabas al juego o te chingaban: plata o plomo» (ICC, 2015:13). Paralelamente, se registraron aumentos sustanciales en los presupuestos para las autoridades judiciales de mayor rango en el ámbito estatal, quienes tienen a su cargo el enjuiciamiento de muchos de los denominados "crímenes de alto impacto» asociados con grupos criminales, incluyendo homicidio, secuestro y extorsión. En Juárez, el incremento correspondiente fue de 2100 millones en 2010 a 4100 millones de pesos mexicanos en 2013. En otras palabras, un incremento del casi $100 \%$ en solo tres años, durante los cuales la economía mexicana solo creció un $12 \%$, aproximadamente (Corcoran, 2016).

No obstante, existiría otra explicación, menos alentadora por cierto, para la disminución de la violencia en Ciudad Juárez que poco o nada tiene que ver con las acciones del Gobierno federal, sino con la dinámica del crimen organizado. De acuerdo a esa línea argumental, las mejoras en seguridad obedecerían principalmente a que la batalla campal entre el Cártel de Sinaloa y el Cártel de Juárez por el control de las rutas que cruzan la ciudad, la cual comenzó en 2008, supuestamente habría llegado a su fin, teniendo el siguiente desenlace: la victoria del Cártel de Sinaloa, liderado por Joaquín el Chapo Guzmán, sobre el Cártel de Juárez. Dado que esa disputa fue el catalizador de violencia más importante durante diez años, podría ser una hipótesis plausible (Corcoran, 2012).

Bajo esa lógica, tras superar en armas a su principal rival, Sinaloa supuestamente habría forzado un pacto de no agresión a fin de dividirse el territorio y así garantizar que el corredor para drogas ilegales a Estados Unidos permaneciera abierto. Conforme a lo señalado por un agente federal mexicano, un muy debilitado Cártel de Juárez pasó a operar en el centro y oeste de la urbe, controlando las ventas de drogas más importantes y la prostitución, así como el acceso a dos puentes internacionales, mientras que el Cártel de Sinaloa controlaría la zona menos poblada al oeste, que tradicionalmente ha sido una ruta principal de tráfico (ICC, 2013: 43-45).

Existen ciertos indicios que apoyarían esta teoría: un elemento clave sería el declive de La Línea, el principal brazo armado del Cártel de Juárez, que durante varios años repelió las fuerzas leales a Guzmán. Y pese a que alguna vez fue un jugador importante en el panorama del narcotráfico en el país, sus conexiones con Colombia y Estados Unidos se han perdido, y el grupo claramente se ha subyugado a los sinaloenses. El cártel no solo ya no constituía una red transnacional real, sino que debería considerarse como una organización criminal de dos niveles, al igual que algunas bandas regionales como Los Aztecas. Por último, como era de esperar, el Cártel de Sinaloa se habría mantenido fiel a su bajo perfil. Esta organización narcotraficante se caracteriza por usar tácticas más suaves y pragmáticas como el soborno y el cobro de comisiones, en lugar de espantosas matanzas (Ramsey, 2012). Con ella al mando del hampa en Juárez, probablemente la violencia asociada al narcotráfico podría haber llegado al mínimo, lo cual explicará la dramática caída en la tasa de homicidios registrada a partir de 2010.

La mejora fue sustancial, aunque la ciudad siguió siendo un lugar relativamente violento. Lo cierto es que en comparación con los tiempos más duros, podría decirse que la zona se ha pacificado. "Juárez ha conseguido un logro incomparable; que ciudades 
como Medellín y Palermo tardaron diez años en hacer lo que acá se ha hecho en tres», indica el fiscal local Enrique Villarreal (Llano, 2013). Este esfuerzo contribuyó a debilitar a los cárteles operativos en el área y ayudó a los gobiernos locales a resistir los intentos violentos de captura del gobierno y de la sociedad civil. Hoy en día ya no se habla de una ciudad caótica. Arturo Valenzuela, portavoz del programa TSJ, aseguró en agosto de 2012 que Juárez había dejado de ostentar el título mundial de «la más violenta» (Zepeda, 2012). Fue así como la vida nocturna tuvo un auge, los restaurantes y pubs volvieron a abrir sus puertas en el centro de la ciudad, las policías volvieron a su rol de vigilantes, terminando así con las rondas de las patrullas militares a las que se acudió como medida de emergencia en el momento más crítico de la situación, y las fábricas comenzaron a contratar trabajadores nuevamente.

Ahora bien, no puede explicarse lo sucedido en Juárez sin considerar el contexto más amplio de guerra contra el narcotráfico impulsada por el expresidente Felipe Calderón en diciembre de 2006, estrategia para la cual TSJ significó un punto de inflexión. A partir de ese momento, Calderón, sin desarticular plenamente el enfoque militarizado, comenzó a pensar en una política de prevención de la violencia que fuera aplicada simultáneamente. Existen versiones diferentes sobre esta nueva orientación, pues algunos piensan que Calderón había percibido los límites de su estrategia y estaba buscando un cambio de rumbo, mientras otros creen que la crisis juarense precipitó este viraje estratégico (Vilalta y Muggah, 2014). De lo que no cabe duda es que la intervención llevada a cabo en el otrora Paso del Norte, basada en un programa extensivo de distribución de bienes y servicios públicos, reflejó un importante cambio de paradigma en la política antinarcóticos del Gobierno federal, mostrando cierta flexibilidad en su enfoque para abordar el crimen y violencia en Juárez: «En lugar de aplicar una solución centrada principalmente en el combate a los cárteles y la captura o abatimiento de capos, el Gobierno dio paso a la prevención de la violencia mediante proyectos sociales» (ICC, 2015: 16).

En esa línea, Bastidas (2010) asegura: «En Ciudad Juárez, [vimos] toda la fuerza del Estado, pero por los resultados, no toda la inteligencia del Estado [...La guerra contra el narcotráfico era] de largo plazo, mucho más profunda, [había que combatirla] con militares y policías, sí, pero también con valores, instituciones y programas sociales. Porque [era] necesario lograr el concurso y participación de toda la sociedad y porque se [requería] mucha inteligencia: de la que ayuda a procesar la información gubernamental y de la que ayuda a comprender la tarea de gobernar y de ejercer un verdadero liderazgo político y social». Vale decir, cada despliegue militar y/u operativo policial debió ir acompañado por un programa de salud pública, un programa educativo, un programa de desarrollo económico, los apoyos a pequeñas y medianas empresas e industrias, un programa urbanístico y medioambiental y, por supuesto, todas las instituciones del Estado de derecho. En efecto, Calderón parece haber aplicado los postulados de Vanda Felbab-Brown y reconceptualizó su respuesta contra los grupos criminales como una competencia entre ambos por la lealtad de la comunidad juarense pues, como se planteó con anterioridad, el crimen organizado tiene un campo abonado de presencia, actividad y captación en áreas donde el acceso a bienes públicos 
y servicios sociales no están garantizados, siendo capaz de asumir funciones paraestatales. En contraste, si se proveen estos servicios a la población y se mejora su bienestar, esto desalentará a los ciudadanos a desarrollar actividades ilícitas como fuente de ingresos y como resultado se reducirá su apoyo a organizaciones narcotraficantes, dificultando aún más su penetración.

TSJ ilustra un exitoso caso en el cual circunstancias excepcionales llevaron a las autoridades municipales a trabajar coordinadamente con sus homólogos federales y estatales, de modo que los esfuerzos oficiales (sumado a una activa sociedad civil, dirigida por líderes empresariales y comunitarios locales que apoyaron los cambios gubernamentales) tuvieron un efecto multiplicador, logrando disminuir la epidemia de violencia criminal hasta niveles previos a la crisis en Juárez, en lugar de trabajar con fines contrapuestos de manera que obstaculice la provisión de seguridad. Como sostiene Héctor Murguía, quien se convirtió en alcalde de aquella urbe en octubre de 2010, cuando el número de asesinatos llegó a su nivel más alto: "No fue una sola acción en especial. Primero, fue la coordinación entre los tres niveles de gobierno: federal, estatal y municipal [...]. Luego lo podemos dividir en dos vertientes: la policíaca y otra, el desarrollo social» (ICC, 2015: 41).

\section{¿PUEDE EMULARSE TSJ?}

Considerando los favorables resultados obtenidos en Juárez surge naturalmente la interrogante: ¡es posible replicar tales logros en otras ciudades del país? Más allá de las lecciones anteriormente enunciadas, sin embargo, aún no queda muy claro lo que TSJ les enseñó a los policy-makers que buscan replicar la misma fórmula en otras ciudades mexicanas que experimentan crisis de seguridad, tales como Acapulco, Monterrey y Culiacán.

Pese a que la iniciativa culminó con la presidencia de Calderón en diciembre de 2012, todavía se desconoce su impacto a largo plazo pues «estos esfuerzos nunca fueron evaluados, por lo que en gran parte se desaprovechó la oportunidad de crear programas innovadores y sostenibles, sujetos a revisión y evaluación externas» (Gagne, 2015). En este sentido, conviene recordar que este programa fue diseñado e implementado con carácter de urgencia, sin apenas planificación ni estrategia. Al respecto, el exsecretario de Gobernación, Alejandro Poiré, explica que «la idea era hacer tanto como fuera posible, tan rápido como fuera posible, hicimos todo sin guión [...]. Juárez ardía, y teníamos que apagar las llamas» (ICC, 2015: 15). Si bien, después de los primeros cien días el Gobierno anunció que se había completado $90 \%$ de los compromisos asumidos, nunca publicó una evaluación final sobre la intervención.

De esa manera, al no realizarse evaluaciones de impacto del programa, el Gobierno federal lamentablemente desaprovechó una valiosa oportunidad para entender mejor qué iniciativas preventivas fueron efectivas y cuáles tuvieron un efecto insignificante sobre la seguridad ciudadana. Sin estos valiosos inputs para la toma de decisiones, es muy difícil determinar con exactitud cómo aplicar políticas eficaces en otras ciudades. 
En ese sentido, las autoridades mexicanas fallaron en Ciudad Juárez, pues el objetivo era aplicar el aprendizaje obtenido en otras urbes sacudidas por la violencia. Como sostiene Enrique Betancourt, quien dirigió el Centro Nacional de Prevención del Delito y Participación Ciudadana durante la administración Calderón: «El objetivo era Juárez, pero la idea hubiera sido desarrollar un plan de impacto colectivo que pudiera ser utilizado en todo el país» (Gagne, 2015).

Como se ha dicho, naturalmente existen múltiples variables que influyen en la violencia urbana, desde problemas socioeconómicos, pasando por dinámicas criminales, hasta la forma en que las autoridades persiguen a los capos. Por ende, la confluencia de muchos de estos factores en Juárez (como la reactivación económica tras la crisis subprime y el aparente término de la guerra entre los cárteles de Sinaloa y Juárez) puede complicar la evaluación de la magnitud del impacto de las acciones gubernamentales en la reducción de violencia, aunque se hayan llevado a cabo seguimientos rigurosos e independientes. Pese a ello, cabe subrayar que en noviembre de 2014 se han creado mesas de trabajo similares a la instrumentada en Juárez en otras diez ciudades de la república mexicana: Tijuana, Cancún, Puebla, León, Coatzacoalcos, Córdoba, Jalapa, Los Cabos, La Paz, Valle de Bravo, Morelia y Villahermosa (Orquiz, 2014). Incluso, algunas de ellas operan en zonas amenazadas por el crimen organizado, como la mesa de Córdoba (Veracruz), un bastión histórico de Los Zetas. Al respecto, Orlando Camacho, director ejecutivo de SOS, una organización no gubernamental que busca promover la experiencia juarense en diferentes ciudades mexicanas asediadas por la violencia criminal, concluye: «La mesa es elástica; se puede adaptar a diferentes circunstancias [...], la idea central es la corresponsabilidad, reunir a las autoridades que toman decisiones con un grupo multidisciplinario de líderes ciudadanos» (ICC, 2015: 23).

\section{CONCLUSIONES}

En el Foro Económico Mundial de 2016, Ciudad Juárez destacó como una de las ciudades latinoamericanas que lograron una notable reducción del crimen y la violencia asociada al narcotráfico, dejando atrás el estigma de ser «la ciudad más peligrosa del mundo». Ante lo anterior cabe preguntarse: ¿cómo se generó tal cambio?

Juárez fue un caso paradigmático del enfoque aplicado durante la Guerra contra el narcotráfico, basado fundamentalmente en la ocupación policiaco-militar. Juárez era una plaza ocupada permanentemente con miles de efectivos desde el Operativo Conjunto Chihuahua en 2008. Nadie puede negar que en Ciudad Juárez, como en ningún otro sitio, se ejecutara a cabalidad y plenitud la visión, diagnóstico y estrategia originalmente concebida por Felipe Calderón ante la crisis de seguridad que vivía México al inicio de su administración. En Juárez, el crimen y la violencia crecieron de forma sistemática debido al rezago social, político y económico de su población, sumado a la creciente desocupación -generada principalmente por la pérdida de empleos en el sector maquilador-, la ineficacia policial, los cambios en el narcotráfico y la ubicación geoestratégica al ser una ciudad fronteriza. 
Sin embargo, el Gobierno federal dio un giro en su enfoque militarizado tras una masacre ocurrida en Villas de Salvárcar, reconociendo que, incluso en la ciudad más violenta del mundo, un ataque frontal a través del despliegue de soldados constituye una medida insuficiente para reducir la violencia criminal. A raíz de este trágico episodio, los operativos fueron acompañados por un inédito programa de ayuda socioeconómica (TSJ), cuyo objetivo era construir comunidades resistentes a la penetración del crimen organizado. De ese modo, la ciudad fronteriza se convirtió no solo en un termómetro de la eficacia de la estrategia de seguridad calderonista, sino también en laboratorio para el diseño de opciones de política alternativas destinadas a abordar esta problemática.

La instrumentación de TSJ se fundamentó en tres pilares estratégicos: enfoque holístico, activa participación ciudadana y coordinación entre los tres niveles de gobierno (federal, estatal y municipal). Pueden extraerse varias lecciones.

En primer lugar, en este programa se observa cómo las autoridades locales cayeron en la cuenta e que la violencia criminal tiene muchas causas. Por tal razón, es preciso realizar una competencia en construcción de Estado (competition in state-making). Si bien el elemento represivo es un componente crucial en la respuesta, a menudo debe complementarse con políticas socioeconómicas orientadas a dar igualdad de oportunidades y atender las necesidades básicas de las comunidades a fin de restaurar el contrato social entre el Estado y los residentes de estas zonas, de modo que se rompa la dependencia de las poblaciones en relación con los enclaves criminales creados por grupos criminales. Esto es debido a que, como se indicó previamente, los grupos criminales se empoderan en barrios marginales, aprovechándose de que los habitantes ven poca presencia gubernamental, con excepción de agentes policiales o efectivos militares. Por ende, las dos variables clave en escenarios tan complejos como el juarense son: la autoridad efectiva del Estado, acompañada de la provisión de bienes y servicios públicos con el objetivo de que la escala de la economía ilícita disminuya y su capacidad de daño se minimice.

En segundo lugar, la activa participación ciudadana es un factor crítico para que cualquier iniciativa contra el crimen sea exitosa. En el caso de TSJ se actuó bajo esa premisa: son los propios juarenses quienes mejor conocen la situación de su ciudad y, por lo tanto, se organizaron mesas de trabajo con representantes de la sociedad civil para conocer sus opiniones y propuestas acerca de la problemática. De hecho, fueron las recomendaciones realizadas por estas mesas las que sirvieron como insumo de los ciento sesenta compromisos gubernamentales, y también las que eligieron a los representantes ciudadanos que vigilarían y harían seguimiento del cumplimiento de los objetivos trazados. Por tanto, la comunidad estaba bien organizada y dispuesta a participar en la reconstrucción de su ciudad. No obstante, en zonas donde este valioso activo escasea, se deben fortalecer las organizaciones sociales. Otro punto importante que debe ser tomado en cuenta es que los jóvenes desocupados son particularmente vulnerables a la delincuencia y la violencia, por lo que deben asumir un protagonismo en el proceso de toma de decisiones para identificar sus propias necesidades y contribuir a desarrollar soluciones innovadoras. 
Finalmente, la coordinación entre los diversos niveles de gobierno es un componente vital para asegurar el alto impacto de cualquier esfuerzo orientado a reducir la violencia criminal. El régimen federal vigente en México es un intrincado conjunto de reglas e instituciones que otorga a las autoridades federales, estatales y municipales responsabilidades específicas. Por tanto, la alineación de los esfuerzos de todas autoridades en un contexto de transición democrática continúa siendo un desafío, sobre todo a lo que seguridad pública se refiere. TSJ demostró que la integración vertical resulta imprescindible si el país pretende tener éxito en la implementación de políticas públicas contra el crimen y la violencia.

\section{AGRADECIMIENTOS}

Este artículo es un producto del Proyecto IN201503, «ंTropas en la calle? Fuerzas Armadas en seguridad pública en México y El Salvador: Una visión comparada», financiado por la Academia Nacional de Estudios Políticos y Estratégicos (ANEPE).

\section{Referencias}

Bastidas, Sabino. 2010. «Ciudad Juárez, resiste». El País Internacional, 9-02-2010. Disponible en: http://internacional.elpais.com/internacional/2010/02/09/actualidad/1265670009_850215.html [Consulta: 24 de mayo de 2016].

Calderón, Felipe. 2012. "Todos Somos Juárez, dos años después», Presidencia de la República, 17-02-2012. Disponible en: http://calderon.presidencia.gob.mx/ el-blog/todos-somos-juarez-dos-anos-despues/. [Consulta: 3 de junio de 2016].

Calderón, Felipe. 2013. «Todos Somos Juarez: An innovative strategy to tackle violence and crime», Latin America Policy Journal Harvard Kennedy School of Government, 21-10-2013. Disponible en: http://hkslapj.com/hello-world/ [Consulta: 17 de febrero de 2016].

Camarena, Salvador. 2012. «El silencio de las balas no ha llevado la paz a Ciudad Juárez», El País Internacional, 20-03-2012. Disponible en: http://internacional. elpais.com/internacional/2012/03/20/actualidad/1332279884_139869.html [Consulta: 23 de marzo de 2016].

Chaparro, Luis. 2013. "Juárez privada: una revolución en seguridad de un pueblo fronterizo", Insight Crime. Centro de Investigación de Crimen Organizado, 10-072013. Disponible en: http://es.insightcrime.org/analisis/juarez-privada-una-revolicion-en-seguridad-de-un-pueblo-fronterizo [Consulta: 13 de junio de 2016].

Corcoran, Patrick. 2011. "Juarez Police Boss promises change in 6 months", Insight Crime. Centro de Investigación de Crimen Organizado, 8-07-2011. Disponible en: http://www.insightcrime.org/news-briefs/juarez-police-boss-promises-change-in-6-months [Consulta: 8 de junio de 2016]. 
Corcoran, Patrick. 2012. “¿s Juárez más segura porque el Chapo ganó la guerra?», Insight Crime. Centro de Investigación de Crimen Organizado, 18-08-2012. Disponible en: http://es.insightcrime.org/analisis/es-juarez-mas-segura-porque-el-chapo-gano-la-guerra [Consulta: 6 de marzo de 2016].

Corcoran, Patrick. 2013. "Reducción de la violencia en Juárez, gran triunfo de Calderón: dice Reporte», Insight Crime. Centro de Investigación de Crimen Organizado, 26-03-2013. Disponible en: http://es.insightcrime.org/analisis/reduccion-de-laviolencia-en-juarez-gran-triunfo-de-calderon-dice-reporte [Consulta: 27 de marzo de 2016].

Corcoran, Patrick. 2016. «Lecciones para México en la baja de la violencia en dos estados fronterizos", Insight Crime. Centro de Investigación de Crimen Organizado, 19-02-2016. Disponible en: http://es.insightcrime.org/analisis/lecciones-mexico-baja-violencia-dos-estados-fronterizos [Consulta: 5 de marzo de 2016].

Escobar, Leopoldo. 2012. «Los mitos sobre la violencia en México». En Defensa del Neoliberalismo. Disponible en: http://www.neoliberalismo.com/10-Mitos.htm [Consulta: 22 de abril de 2016].

EFE. 2010. "Calderón condena el "cobarde» asesinato de 16 jóvenes en Ciudad Juárez», $A B C$. Disponible en: http://www.abc.es/agencias/noticia.asp?noticia= 257609 [Consulta: 8 de junio de 2016].

Felbab-Brown, Vanda. 2010. "Conceptualizing crime as competition in state-making and designing an effective response». Brookings. On the Record, 21-05-2010. Disponible en: http://www.brookings.edu/research/speeches/2010/05/21-illegal-economies-felbabbrown [Consulta: 2 de julio de 2016].

Felbab-Brown, Vanda. 2011a. Bringing the State to the Slum: Confronting Organized Crime and Urban Violence in Latin America. Washington, D. C.: The Brookings Institution.

Felbab-Brown, Vanda. 2011b. Calderón's Caldron: Lessons from Mexico's battle against organized crime and drug trafficking in Tijuana, Ciudad Juárez, and Michoacán. Washington, D. C.: The Brookings Institution.

Felbab-Brown, Vanda. 2013. "Crime-War Battlefields», Survival, 55 (3): 147-66. Disponible en: https://doi.org/10.1080/00396338.2013.802859

Geneva Centre for the Democratic Control of Armed Forces (DCAF). 2012. Armed Non-State Actors: Current Trends and Future Challenges. Geneva: DCAF and Geneva Call.

Gagne, David. 2015. «¿Por qué será difícil duplicar los logros de seguridad en Juárez?» Insight Crime. Centro de Investigación de Crimen Organizado, 24-03-2015. Disponible en: http://es.insightcrime.org/analisis/dificil-duplicar-logros-seguridad-juarez [Consulta: 24 de marzo de 2016].

García, José. 2014. «En 14 meses no han habido secuestros en Cd. Juárez: PGJ», Milenio, 9-11-2014. Disponible en: http://www.milenio.com/policia/secuestros_Cd_ Juarez-bajan_secuestros_Cd_Juarez-Fiscalia_Chihuahua_0_406159630.html [Consulta: 20 de mayo de 2016]. 
Guerrero, Eduardo. 2010. «Cómo reducir la violencia en México», Nexos, 1-11-2010. Disponible en: http://www.nexos.com.mx/?p=13997 [Consulta: 2 de julio de 2016]. International Crisis Group (ICC). 2013. El desafio de Peña Nieto: los cárteles criminales $y$ el Estado de derecho en México. Bruselas: International Crisis Group.

International Crisis Group (ICC). 2015. Ciudad Juárez: ¿Transitando del abismo a la redención? Bruselas: International Crisis Group.

Llano, Pablo. 2013. «Ciudad Juárez, paz entre cadáveres», El País Internacional, 8-122013. Disponible en: http://internacional.elpais.com/internacional/2013/12/06/ actualidad/1386331573_929940.html [Consulta: 23 de junio de 2016].

Lohmuller, Michelle. 2015. «Teoría de ventanas rotas de Giuliani no servirá en Centroamérica», Insight Crime. Centro de Investigación de Crimen Organizado, 19-03-2015. Disponible en web: http://es.insightcrime.org/analisis/teoria-ventanas-rotas-giuliani-no-servira-centroamerica [Consulta: 19 de marzo de 2016].

Martínez, Fabiola. 2013. «El programa Todos Somos Juárez, modelo a aplicar a escala nacional», La Jornada, 15-02-2013. Disponible en: http://www.jornada.unam. $\mathrm{mx} / 2013 / 02 / 15 /$ politica/003n1 pol [Consulta: 4 de marzo de 2016].

Medellín, Jorge. 2009. «Juárez bajo sitio militar», El Universal, 01-03-2009. Disponible en: http://archivo.eluniversal.com.mx/nacion/166104.html [Consulta: 15 de marzo de 2016].

Mesa de Seguridad. 2012. Comisión Indicadores. Cd. Juárez, Chihuahua: Gobierno de México.

Meyer, Maureen. 2010. Abuso y miedo en Ciudad Juárez. Washington D. C.: WOLA. Milo, Alexis. 2011. "Todos Somos Juárez: una estrategia integral», Presidencia de la República, 26-05-2011. Disponible en: http://calderon.presidencia.gob.mx/ el-blog/estrategia-todos-somos-juarez/ [Consulta: 26 de mayo de 2016].

Muggah, Robert y Ilona Szabó de Carvalho. 2016. Making Cities Safer: Citizen Security Innovations from Latin America. Rio de Janeiro: Igrapé Institue.

Olivares, Emir. 2009. «Ineficientes, las políticas de Calderón en rubros prioritarios», La Jornada, 23-07-2009. Disponible en: http://www.jornada.unam.mx/2009/ 07/23/politica/003n1pol [Consulta: 15 de abril de 2016].

Orquiz, Martín. 2014. «Crean aquí Red Nacional de Mesas de Seguridad», El Diario, 05-11-2014 Disponible en: http://diario.mx/Local/2014-11-05_81b0e3d7/ crean-aqui-red-nacional-de-mesas-de-seguridad/ [Consulta: 15 de abril de 2016].

Pachico, Elyssa. 2013. «Tasa de homicidios en Juárez llega a su nivel más bajo en cinco años", Insight Crime. Centro de Investigación de Crimen Organizado, 04-01-2013. Disponible en: http://es.insightcrime.org/analisis/tasa-de-homicidios-en-juarezllega-a-su-nivel-mas-bajo-en-cinco-anos [Consulta: 4 de marzo de 2016].

Patterson, Pat y Cristina Blain. 2014. «Derechos Humanos y la Lucha Contra las Organizaciones Criminales Transnacionales: Una Estrategia Imprescindible», Security and Defense Studies Review, 16: 57-67.

Petersen, Diego. 2010. "Cuando todo falle...", El País Internacional, 13-02-2010. Disponible en: http://elpais.com/elpais/2010/02/13/opinion/1266053939_850215. html [Consulta: 23 de marzo de 2016]. 
Ramsey, Geoffrey. 2012. «A pesar de la agitación del bajo mundo en México, la paz seguirá siendo incierta en Juárez», Insight Crime. Centro de Investigación de Crimen Organizado, 26-10-2012. Disponible en: http://es.insightcrime.org/analisis/a-pesar-de-la-agitacion-del-bajo-mundo-de-mexico-seguira-en-pie-la-paz-incierta-dejuarez [Consulta: 22 de abril de 2016].

Redacción. 2011. "Ciudad Juárez, por tercer año consecutivo, la urbe más violenta del planeta», Seguridad Justicia y Paz, 12-01-2011. Disponible en: http://www.seguridadjusticiaypaz.org.mx/sala-de-prensa/329-ciudad-juarez-por-tercer-ano-consecutivo-la-urbe-mas-violenta-del-planeta [Consulta: 27 de mayo de 2016].

Stevenson, Mark. 2010. «Police take over from army in Mexico border city», Ventura County Star, 08-04-2010. Disponible en web: http://www.vcstar.com/news/police-take-over-from-army-in-mexico-border-city-ep-369291199-349904311.html [Consulta: 25 de abril de 2016].

Vargas, Laura. 2012. «Juarez: a story of resilience», World Policy Institute, 24-04-2012. Disponible en: http://www.worldpolicy.org/blog/2012/04/24/ju\%C3\%A1 rez-storyresilience [Consulta: 23 de mayo de 2016].

Vilalta, Carlos y Robert Muggah. 2014. «Violent disorder in Ciudad Juarez: a spatial analysis of homicide», Trends in Organized Crime, 17 (3): 161-180. Disponible en: https://doi.org/10.1007/s12117-014-9213-0

Villalobos, Joaquín. 2010. «Doce mitos de la guerra contra el narco», Nexos, 01-012010. Disponible en: http://www.nexos.com.mx/?p=13461 [Consulta: 18 de marzo de 2016].

Villalobos, Joaquín. 2015. «Bandidos, Estado y ciudadanía», Nexos, 01-01-2015. Disponible en: http://www.nexos.com.mx/?p=23788 [Consulta: 19 de junio de 2016].

Wilkinson, Tracy. 2010. "Calderon visits Ciudad Juarez», Los Angeles Times, 12-022010. Disponible en: http://articles.latimes.com/2010/feb/12/world/la-fg-mexico-juarez12-2010feb12 [Consulta: 25 de abril de 2016].

Zepeda, Marco. 2012. «¿Se terminó la guerra del narco en Ciudad Juárez?: WP», Animal Político, 20-08-2012. Disponible en: http://www.animalpolitico.com/2012/08/ se-termino-la-guerra-del-narco-en-chihuahua-wp/ [Consulta: 27 de abril de 2016].

Presentado para evaluación: 5 de julio de 2016.

Aceptado para publicación: 16 de enero de 2017.

\section{ESTEBAN ARRATIA}

jarratia@anepe.cl

Analista en políticas y asuntos internacionales, mención en Seguridad y Defensa, Universidad de Santiago. Magíster en Estudios Internacionales, Universidad de Santiago. Investigador asociado de la Academia Nacional de Estudios Políticos y Estratégicos. 